EPJ manuscript No.

(will be inserted by the editor)

\title{
Copper and copper oxide nanoparticles in a cellulose support studied using anomalous small-angle $x$-ray scattering
}

\author{
U. Vainio ${ }^{1}$, K. Pirkkalainen ${ }^{1}$, K. Kisko ${ }^{1}$, G. Goerigk ${ }^{2}$, N. E. Kotelnikova ${ }^{3}$, and R. Serimaa ${ }^{1}$ \\ 1 Division of X-ray Physics, Department of Physical Sciences, P.O.Box 64, FI-00014 University of Helsinki, Finland, e-mail: \\ ritva.serimaa@helsinki.fi, Tel: +358-9-19150630 Fax: +358-9-19150639 \\ 2 Institut für Festkörperforschung, Forschungszentrum Jülich, Postfach 1913, 52425 Jülich, Germany \\ 3 Institute of Macromolecular Compounds, Russian Academy of Sciences, Bolshoy pr. 31, St. Petersburg 199004, Russia
}

Received: date / Revised version: date

\begin{abstract}
Microcrystalline cellulose is a porous natural material which can be used both as a support for nanoparticles and as a reducer of metal ions. Cellulose supported nanoparticles can act as catalysts in many reactions. $\mathrm{Cu}, \mathrm{CuO}$, and $\mathrm{Cu}_{2} \mathrm{O}$ particles were prepared in microcrystalline cellulose by adding a solution of copper salt to the insoluble cellulose matrix and by reducing the copper ions with several reducers. The porous nanocomposites were studied using anomalous small angle x-ray scattering (ASAXS), x-ray absorption spectroscopy, and x-ray diffraction. Reduction of $\mathrm{Cu}^{2+}$ with cellulose in ammonium hydrate medium yielded crystalline $\mathrm{CuO}$ nanoparticles and the crystallite size was about $6-20 \mathrm{~nm}$ irrespective of the copper concentration. The size distribution of the $\mathrm{CuO}$ particles was determined with ASAXS measurements and coincided with the crystallite sizes. Using sodium borohydrate or hydrazine sulfate as a reducer both metallic $\mathrm{Cu}$ and $\mathrm{Cu}_{2} \mathrm{O}$ nanoparticles were obtained and the crystallite size and the oxidation state depended on the amount of reducer.
\end{abstract}

PACS. 61.10.Eq X-ray scattering (including small-angle scattering) - 61.10.Ht X-ray absorption spectroscopy: NEXAFS, XANES - 61.46.Df Nanoparticles

\section{Introduction}

Porous supports are used mostly to enhance the catalytic activity of metals and metal oxides. A multitude of different supports have been invented and used, but not many of them are biodegradable, economical, widely available, and easy to make. On the other hand, natural polymers have been used as supports and stabilizers for biologically active compounds already for decades $[1,2]$. In most cases, cellulose can be considered as an inert matrix [3], but drugs have also exhibited prolonged activity [4] when impregnated in cellulose. Cellulose and modified cellulosic materials are also used as sorbents of metal ions from aqueous solutions $[5,6]$.

The porous cellulose matrix has been described as a nanoreactor for metal nanoparticles $[7,8]$ and it has been shown to be a useful support material for platinum, palladium, silver, and nickel nanoparticles [2,7,9-11]. Bacterial cellulose supported $\mathrm{Pd}$ was found to be capable of catalysing the generation of hydrogen and to be a suitable polyelectrolyte membrane for fuel cells [10]. The study of the activity of a cellulose supported aqueous phase Pdcatalyst for an allylic substitution reaction showed that catalytic activity depended on the amount of water on the

Send offprint requests to: Ritva Serimaa support. The increase in the specific surface area of cellulose caused by swelling was expected to have an increase in the activity. [12] Recently cellulose supported $\mathrm{Cu}$ was found to be a possible recoverable catalyst for $N$-arylation of nitrogen heterocycles with a variety of aryl halides and arylboronic acids without using external ligands or additives as promoters [13].

Detailed knowledge on the binding of copper onto the cellulose matrix under different conditions is needed. For example the catalytic activity of a catalyst depends on the morphology of the catalyst and therefore also on the type of the substrate [14]. For inorganic supports the best activity for $\mathrm{NO}$ oxidation has been observed when $\mathrm{Cu}^{2+}$ ions were dispersed onto the support. $\mathrm{CuO}$ nanoparticles of only a few nanometers in size showed lower catalytic activity [15].

The control of copper nanoparticle size and oxidation has been studied for several types of synthesis routes $[16$, 17]. Lisiecki et al. [18] synthesized nanosized copper crystallites in reverse micelles and in gelified microemulsions. They reported that by using hydrazine as a reducer the control of the size $(2-12 \mathrm{~nm})$ and the oxidation state was achieved. Using a strong reducing agent, sodium borohydride $\mathrm{NaBH}_{4}$, the control of the oxidation state and the particle size was not so efficient. The environmental burden is small when the synthesis is done in an aqueous so- 
lution, but the control over the particle size and oxidation state is not trivial when using chemical reduction without additives. Ideally one would like to be able to control these parameters by adjusting the molar ratio of the metal ions to the cellulose monomer unit and by the amount of reducers.

The size distribution of nanoparticles in a porous matrix can be studied using anomalous small-angle x-ray scattering (ASAXS). With this technique the partial structure factor of the nanoparticles can be solved from a set of intensities measured at different energies. [19] When properly used, ASAXS gives quantitative structural information on the nm-size scale [20]. Scanning electron microscopy (SEM) gives the size of the particles on the surface of the matrix at larger length scales. X-ray absorption spectroscopy reveals the chemical state of the metal atoms in the nanoparticles. The crystalline structure and the size of crystallites can be obtain using x-ray diffraction (XRD).

In this work $\mathrm{Cu}^{2+}$-ions were reduced within an insoluble microcrystalline cellulose (MCC) matrix using several reducers in order to study how the average size and crystallization of the copper and copper oxide nanoparticles are affected by the reducing agent. The nanocomposites were studied using ASAXS, x-ray absorption spectroscopy, XRD, and SEM. The ASAXS method is rarely used on quantitative level and thus the method is described here in detail.

\section{Experimental}

\subsection{Samples}

The MCC-Cu nanocomposites were prepared by adding copper salt, copper acetate $\mathrm{Cu}\left(\mathrm{CH}_{3} \mathrm{COO}\right)_{2}$ (samples 1 7) or copper sulfate $\mathrm{CuSO}_{4}$ (samples 8 - 15), in aqueous, ammonium hydrate $\left(\mathrm{NH}_{3} \cdot \mathrm{H}_{2} \mathrm{O}\right)$ or glycerol medium $(0.075 \mathrm{M})$ to a cellulose matrix prepared of cotton cellulose by mild acid hydrolysis. The $\mathrm{Cu}^{2+}$-ions were reduced directly by MCC using its reducing properties (A), by sodium borohydride $\mathrm{NaBH}_{4}(\mathrm{~B})$, or by hydrazine sulfate $\mathrm{N}_{2} \mathrm{H}_{4} \cdot \mathrm{H}_{2} \mathrm{SO}_{4}(\mathrm{C})$. When $\mathrm{N}_{2} \mathrm{H}_{4} \cdot \mathrm{H}_{2} \mathrm{SO}_{4}$ was used as the reducer the $\mathrm{pH}$ of the reaction mixture was kept at 8.5 by adding $\mathrm{NaOH}$. After $1 \mathrm{~h}$ reaction time at $95^{\circ} \mathrm{C}$ the samples were washed with water and dried in vacuum at $40^{\circ} \mathrm{C}$. According to elemental analysis (Hewlett-Packard $\mathrm{C}, \mathrm{H}, \mathrm{N}$-analyser) the mass percent of $\mathrm{Cu}$ in the reduced and dried samples in the bulk was from 1 to $9 \%$ in reasonable correlation with x-ray absorption data according to which the mass percent of copper in the samples ranged from 1 to $13 \%$ with relative error up to $2 \%$. Basic data on the samples are given in Table 1.

\subsection{Scanning electron microscopy}

In micrometer range the morphology of the microcrystalline cellulose samples and those subjected to chemical treatments were studied by scanning electron microscopy using
Table 1. The samples and the sample preparation parameters. $\mathrm{Cu}^{2+} / \mathrm{MCC}$ is the molar ratio of $\mathrm{Cu}^{2+}$ ions to a cellulose monomer unit and $\mathrm{Cu}^{2+} /$ gly is the molar ratio of $\mathrm{Cu}^{2+}$ ions to a glycerol molecule. $\mathrm{A}=$ Molar ratio $\mathrm{NH}_{3} / \mathrm{Cu}^{2+}, \mathrm{B}=$ Molar ratio $\mathrm{BH}_{4} / \mathrm{Cu}^{2+}$, and $\mathrm{C}=$ Molar ratio $\mathrm{N}_{2} \mathrm{H}_{4} \cdot \mathrm{H}_{2} \mathrm{SO}_{4} / \mathrm{Cu}^{2+}$. el $=\% \mathrm{Cu}$ according to elemental analysis. $\mathrm{x}=\% \mathrm{Cu}$ according to x-ray absorption.

\begin{tabular}{|c|c|c|c|c|c|c|}
\hline \multirow[b]{2}{*}{ \# } & \multirow{2}{*}{\multicolumn{2}{|c|}{$\begin{array}{l}\mathrm{Cu}^{2+} / \\
\mathrm{MCC}\end{array}$}} & \multirow[b]{2}{*}{ Medium } & \multirow{2}{*}{$\begin{array}{l}\mathrm{Cu}^{2+} / \\
\text { gly }\end{array}$} & \multicolumn{2}{|c|}{$\% \mathrm{Cu}$} \\
\hline & & & & & el & $\mathrm{x}$ \\
\hline & & A & & & & \\
\hline 1 & 0.1 & 0 & $\mathrm{H}_{2} \mathrm{O}$ & - & 1.0 & 0.9 \\
\hline 2 & 0.2 & 3.0 & $\mathrm{NH}_{3} \cdot \mathrm{H}_{2} \mathrm{O}$ & 2.6 & 1.4 & 2.3 \\
\hline 3 & 0.3 & 4.0 & $\mathrm{NH}_{3} \cdot \mathrm{H}_{2} \mathrm{O}$ & 4.0 & 3.5 & 4.2 \\
\hline 4 & 0.3 & 4.0 & $\mathrm{NH}_{3} \cdot \mathrm{H}_{2} \mathrm{O}$ & - & 5.4 & 6.7 \\
\hline 5 & 0.5 & 3.0 & $\mathrm{NH}_{3} \cdot \mathrm{H}_{2} \mathrm{O}$ & - & 5.5 & 8.6 \\
\hline 6 & 0.6 & 4.0 & $\mathrm{NH}_{3} \cdot \mathrm{H}_{2} \mathrm{O}$ & - & 8.6 & 13.0 \\
\hline 7 & 1.0 & 3.0 & $\mathrm{NH}_{3} \cdot \mathrm{H}_{2} \mathrm{O}$ & - & 8.7 & 10.0 \\
\hline & & $\bar{B}$ & & & & \\
\hline 8 & 0.4 & 1.2 & $\mathrm{H}_{2} \mathrm{O}$ & 5.3 & 3.5 & 4.6 \\
\hline 9 & 0.4 & 2.0 & $\mathrm{H}_{2} \mathrm{O}$ & 5.3 & 3.8 & 6.3 \\
\hline 10 & 0.4 & 2.5 & $\mathrm{H}_{2} \mathrm{O}$ & 5.3 & 4.0 & 8.1 \\
\hline 11 & 0.4 & 2.5 & $\mathrm{H}_{2} \mathrm{O}$ & - & 4.2 & 9.7 \\
\hline & & $\mathrm{C}$ & & & & \\
\hline 12 & 0.25 & 0.2 & $\mathrm{H}_{2} \mathrm{O}$ & - & 8.0 & 9.7 \\
\hline 13 & 0.25 & 2.9 & $\mathrm{H}_{2} \mathrm{O}$ & - & 6.5 & 10.2 \\
\hline 14 & 0.25 & 3.4 & $\mathrm{H}_{2} \mathrm{O}$ & - & 7.2 & 9.3 \\
\hline 15 & 0.25 & 3.9 & $\mathrm{H}_{2} \mathrm{O}$ & - & 7.1 & 8.8 \\
\hline
\end{tabular}

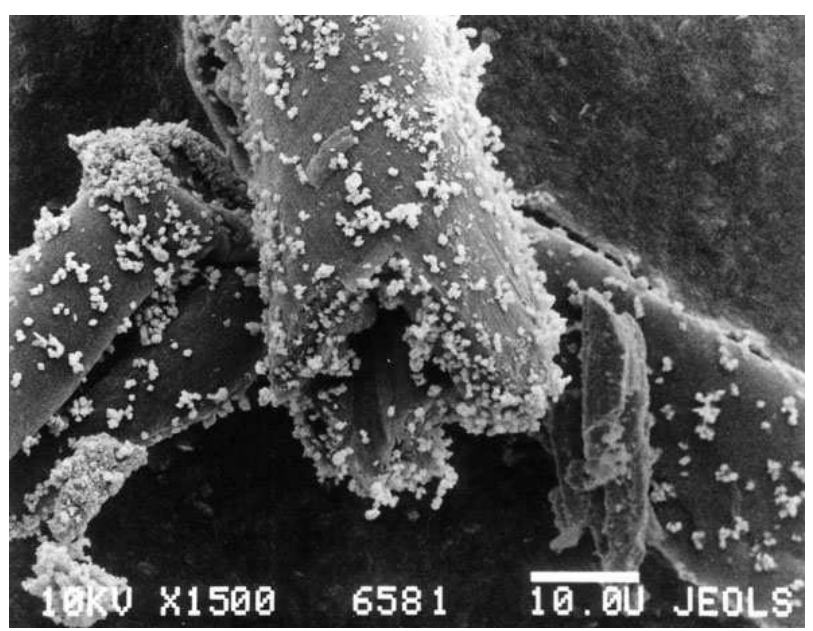

Fig. 1. Scanning electron micrograph of the fibres of a MCC$\mathrm{Cu}$ nanocomposite (the sample 15). Light spots on the surface of the MCC fibre are $\mathrm{Cu}^{0}$ particles. The reducer was $\mathrm{N}_{2} \mathrm{H}_{4} \cdot \mathrm{H}_{2} \mathrm{SO}_{4}$. The scale bar is $10 \mu \mathrm{m}$.

a Jeol JCM-35 CF ("Jeol", UK) instrument. To obtain micrographs, the samples were preliminarily mounted on an aluminium support covered with a carbon layer in a special chamber, then sputtered under inert gas using a gold target. A SEM figure of the sample 15 is shown in Fig. 1. 


\section{$2.3 \mathrm{X}$-ray absorption}

X-ray absorption measurements and ASAXS measurements were conducted at the experimental station JUSIFA B1 at Hamburg Synchrotron Radiation Laboratory (HASYLAB) in Germany [21]. The sample powders were put in steel rings (thickness $0.8 \mathrm{~mm}$ ) sealed Kapton windows. The size of the beam was $1 \mathrm{~mm}^{2}$ and thus the results presented are statistically meaningful and represent the whole sample.

The absorption of each sample at the $\mathrm{Cu}$ K-edge was determined by tuning the energy of the radiation from $8970 \mathrm{eV}$ to $9005 \mathrm{eV}$ in steps of $1 \mathrm{eV}$ and measuring the flux of the direct beam and that of the beam transmitted by the sample with a diode attached inside the sample chamber. The energy scale was calibrated using a copper foil which was measured at the beginning and the end of the measurement time. The accuracy of the energy scale was $0.2 \mathrm{eV}$. In order to determine the anomalous scattering factors $f^{\prime}$ and $f^{\prime \prime}$ the absorption of the samples 1, 3, 12 , and 15 was measured at an energy interval of $8600 \mathrm{eV}$ $-9400 \mathrm{eV}$ two times.

The mass fraction of copper (Table 1) can be extracted from the unnormalised absorption $\mu(E) D$. The experimental intensity at the pre-edge region and at the afteredge region were fitted with straight lines in order to determine the edge jump. The theoretical edge jump in the mass absorption coefficient $\mu / \rho$ is $247.208 \mathrm{~cm}^{2} / \mathrm{g}$ for $\mathrm{Cu}$ K-edge [22].

The mass fraction of copper, $w^{\mathrm{Cu}} \mathrm{\text { }}$, in the sample was calculated as [23]

$$
w_{\mathrm{Cu}}=\frac{A \Delta(\mu D)}{m_{s} \Delta(\mu / \rho)},
$$

where $\mu$ is the linear absorption coefficient, $D$ is the sample thickness, $\Delta(\mu D)$ is the edge jump, and $\Delta(\mu / \rho)$ is the theoretical edge jump. The area of the sample is $A$ and the mass of the sample is $m_{s}$.

The $\mathrm{x}$-ray absorption near edge structure (XANES) data were normalised by subtracting the line fitted to the region below the edge and by fitting a line above the edge for which the absorption was set to 1 at $9000 \mathrm{eV}$. The anomalous scattering factors, $f^{\prime}$ and $f^{\prime \prime}$, were calculated using the program CHOOCH 4.0 [24]. Table 2 collects the used energies and the experimental and theoretical values of $f^{\prime}$ and $f^{\prime \prime}[25]$.

\subsection{Anomalous small-angle $x$-ray scattering (ASAXS)}

The ASAXS intensities were measured at three or five energies below the $\mathrm{K}$ absorption edge of $\mathrm{Cu}$ (Table 2). The data was collected using a multi-wire area detector. The sample-to-detector distances of $935 \mathrm{~mm}$ and $3635 \mathrm{~mm}$ were used. Here the magnitude of the scattering vector is defined as $q=4 \pi \sin \theta / \lambda$, where $\lambda$ is the wavelength and $2 \theta$ is the scattering angle. By comparing intensities of a pure MCC sample at different energies the reliable $q$-range was concluded to be from 0.016 to $0.45 \AA^{-1}$. A typical
Table 2. Measurement energies and corresponding anomalous scattering factors $f^{\prime}$ and $f^{\prime \prime}$ for the samples $3(\mathrm{CuO}), 12$ $\left(\mathrm{Cu}_{2} \mathrm{O}\right)$, and $15\left(\mathrm{Cu}^{0}\right)$. Brackets indicate the values obtained for the sample 15. The values for $f^{\prime}$ and $f^{\prime \prime}$ in [ ] are theoretical.

\begin{tabular}{lrrr}
\hline$\#$ & $\mathrm{E}(\mathrm{eV})$ & $\mathrm{f}$ & $\mathrm{f}$ \\
\hline 3 & 8447.6 & {$[-2.46]$} & {$[0.54]$} \\
& 8959.4 & $-5.51[-5.80]$ & $0.53[0.49]$ \\
& 8979.0 & $-6.96[-8.29]$ & $0.66[2.62]$ \\
\hline 12 & 8442.7 & {$[-2.45]$} & {$[0.54]$} \\
$(15)$ & 8865.1 & $-3.97(-3.97)[-3.95]$ & $0.49(0.49)[0.49]$ \\
& 8954.5 & $-5.40(-5.42)[-5.56]$ & $0.48(0.49)[0.48]$ \\
& 8974.1 & $-6.62(-6.66)[-7.43]$ & $0.58(0.59)[0.12]$ \\
& 8982.0 & $-7.95(-7.56)[-8.02]$ & $1.94(1.84)[4.19]$ \\
\hline
\end{tabular}

ASAXS measurement of one sample at one energy took 20 minutes.

The ASAXS data were processed with the software available at the beam line. The program was used to integrate, to correct for transmission and detector sensitivity, to subtract the dark current and the background and to combine the scattering curves obtained at different distances. It was also used to put the intensities onto absolute scale $\left(\mathrm{cm}^{-1}\right)$ using glassy carbon measurements. Matlab was used to subtract the energy dependent constant background from the intensities so that the power law at large $q$ was the same for all intensities from the same sample.

\subsubsection{Analysis of ASAXS data}

The MCC-Cu nanocomposites were described as two-component systems consisting of MCC (a) and copper (b). The x-ray scattering intensity $I(q)$ was written as $[26]$

$$
\begin{aligned}
I(q, E) & =x_{\mathrm{a}}\left|f_{\mathrm{a}}(q, E)\right|^{2} S_{\mathrm{aa}}(q) \\
& +2 x_{\mathrm{b}} \Re\left[f_{\mathrm{a}}(q, E) f_{\mathrm{b}}(q, E)\right] S_{\mathrm{ab}}(q) \\
& +x_{\mathrm{b}}\left|f_{\mathrm{b}}(q, E)\right|^{2} S_{\mathrm{bb}}(q),
\end{aligned}
$$

where $f(q, E)=f_{0}(q)+f^{\prime}(E)+i f^{\prime \prime}(E)$ is the scattering factor, $x_{\mathrm{a}}$ and $x_{\mathrm{b}}$ are the atomic fractions of the components a and b, and $S_{\mathrm{aa}}(q), S_{\mathrm{ab}}(q)$, and $S_{\mathrm{bb}}(q)$ are the partial structure factors (PSFs). The anomalous scattering factors $f^{\prime}$ and $f^{\prime \prime}$ are significant only near the absorption edges of elements, while elsewhere the term $f_{0}$ dominates. In the small-angle scattering region we have assumed $f_{0}=Z$. For MCC the terms $f_{\mathrm{a}}^{\prime}$ and $f_{\mathrm{a}}^{\prime \prime}$ are assumed to be zero. Eq. 2 can be presented as a linear equation for each $q$-value as

$$
\mathbf{I}=\mathbf{A S}
$$

where $\mathbf{I}$ is a column vector of intensities $I(q, E), \mathbf{S}$ is a column vector of the partial structure factors, and $A$ is the coefficient matrix. The solved PSFs are affected by statistical errors of the intensities, errors in the normalization of the intensities onto the absolute intensity scale, and errors in $f_{\mathrm{b}}^{\prime}$ or $f_{\mathrm{b}}^{\prime \prime}$ [27]. The effect of small errors may be huge: $S_{\mathrm{ab}}(q)$ may become a negative mirror image of 
the dominating $S_{\mathrm{bb}}(q)$, while $S_{\mathrm{aa}}(q)$ may become a positive mirror image of $S_{\mathrm{bb}}(q)$. The effects of both statistical errors and errors in $f_{\mathrm{b}}^{\prime}$ were studied using simulated data.

\subsubsection{Derivative method}

In addition to solving the equation 3 , we also used a socalled derivative method [26,28]. Eq. 2 was derivated with respect to $f_{\mathrm{b}}^{\prime}$ and a line $(y=a x+b)$ was fitted with the least squares minimization routine at each $q$ to $\left(\mathrm{Z}+f_{\mathrm{b}}^{\prime}\right.$, $\left.d I / d f_{\mathrm{b}}^{\prime}\right)$. The slope $a \propto S_{\mathrm{bb}}(q)$ and the cross-term $S_{\mathrm{ab}}(q)$ can be extracted from the fitted constant $b$.

\subsubsection{Particle size distribution}

Based on the SEM results the particles can be approximated as spherical but vary in shape in the micrometer range. In the nanometer range $S_{\mathrm{bb}}(q)$ gives information on the size distribution of the nanoparticles, if the scattering from large aggregates is restricted to very small angles. In a "dilute" case, where particles are spheres of different sizes, the intensity can be written as

$$
I(q)=\sum_{n=1}^{N} \nu\left(R_{n}\right) I\left(q, R_{n}\right)
$$

Here $\nu\left(R_{n}\right)$ is the volume fraction of spheres of radius $R_{n}$ in the sample while the intensity of the sphere of radius $R_{n}$ is $[29]$

$$
I\left(q, R_{n}\right)=\left(\Delta \rho \frac{4}{3} \pi R_{n}^{3}\right)^{2} \frac{9\left(\sin q R_{n}-q R_{n} \cos q R_{n}\right)^{2}}{\left(q R_{n}\right)^{6}}
$$

where $\Delta \rho$ is the electron density difference between the sphere and the surroundings. The volume distribution function is defined here as $D(R)=\nu(R) V(R)$, where $V(R)$ is the volume of a sphere $\frac{4}{3} \pi R^{3}$. In this approach the interparticle interference effects are neglected.

The particle size distribution was retrieved from $S_{\mathrm{bb}}(q)$ using a Monte Carlo fitting similar to the one described in [30]. The reason we chose the Monte Carlo method instead of other methods is the fact that it does not assume any predetermined shape for the distribution and is not very sensitive to noise in the data. Structure factors of spheres of different radius were picked randomly from an array of structure factors of spheres of radii $R=5 \AA$ to $R=160 \AA$ with $4 \AA$ steps.

The Monte Carlo simulation was run 1000 times with 400000 random trials per each fitted curve. The particle size distribution curve was then an average over the accepted curves which had goodness of fit close to one. Number of accepted solutions ranged from 200 to 600 depending on the sample.

\subsubsection{PSF simulation}

For the studying of the reliability of the partial structure factors a set of simulated intensity curves was generated.

The simulation showed that if the absolute intensity at any of the three energies is multiplied by a factor 1.001 even the most dominating PSF, $S_{\mathrm{bb}}(q)$, will be affected. The larger the error of the intensity level the more the PSF will resemble the original intensity. The only way to avoid this problem is to measure the absolute intensity calibration standard with excellent accuracy and to measure the sample and standard many times at each energy with short measurement times.

Instead of PSFs one often uses the differential structure factors (DSF), $I_{2}-I_{1}$. If the cross term $S_{\mathrm{ab}}(q)$ can be assumed to be close to zero then the DSF equals the PSF of copper. The cross term is large at low $q$ comparable to the sizes of the particles, namely $q<2 \pi / 100 \AA \approx 0.06 \AA^{-1}$ and close to zero at higher $q$-values. At the $q$-range studied here the cross-term gives a contribution at low $q$. If the DSFs would be used to solve the particle size distributions the distributions would be skewed to contain a higher proportion of large particles than there actually were in the samples.

\subsection{X-ray diffraction}

The wide-angle $\mathrm{x}$-ray scattering measurements (WAXS) on the same samples as in the ASAXS experiments were conducted using the perpendicular transmission geometry. Characteristic $\mathrm{Cu} K \alpha$ radiation from a sealed anode $\mathrm{x}$-ray tube (point focus) was used. A Molecular Dynamics image plate was used as a detector. The transmission of the samples was measured with a HI-Star Area detector (Bruker AXS). The intensities were corrected for absorption and a geometrical correction was applied to compensate for the detector flatness.

The average size of the crystallites, $B_{h k l}$, was determined using the Scherrer formula

$$
B_{h k l}=\frac{0.9 \lambda}{\sqrt{(\Delta 2 \theta)_{h k l}^{2}-(\Delta 2 \theta)_{\mathrm{inst}}^{2}} \cos \theta_{h k l}},
$$

where $2 \theta_{h k l}$ is the position of the $h k l$ reflection, $(\Delta 2 \theta)_{h k l}$ is the full width at half maximum (FWHM) of the reflection $h k l$ in radians and $(\Delta 2 \theta)_{\text {inst }}$ is the instrumental broadening of the reflection [29].

Gaussian functions with linear backgrounds were fitted to the diffraction peaks. The instrumental broadening of the peaks was estimated from $\mathrm{Si} 111$ reflection at $2.0 \AA^{-1}$ to be $0.40 \pm 0.05^{\circ}$. The error of the crystallite size was estimated using the error propagation law.

Some of the samples were pressed into pellets of about $1 \mathrm{~cm}$ in diameter and $0.6 \mathrm{~mm}$ in thickness for measurements with a diffractometer in symmetrical reflection geometry using $\mathrm{CuK} \alpha_{1}$ radiation. The instrumental broadening was determined to be $0.21 \pm 0.01^{\circ}$ using an Avicel$\mathrm{NaCl}$ sample (9:1). The accuracy of the diffractometer was 

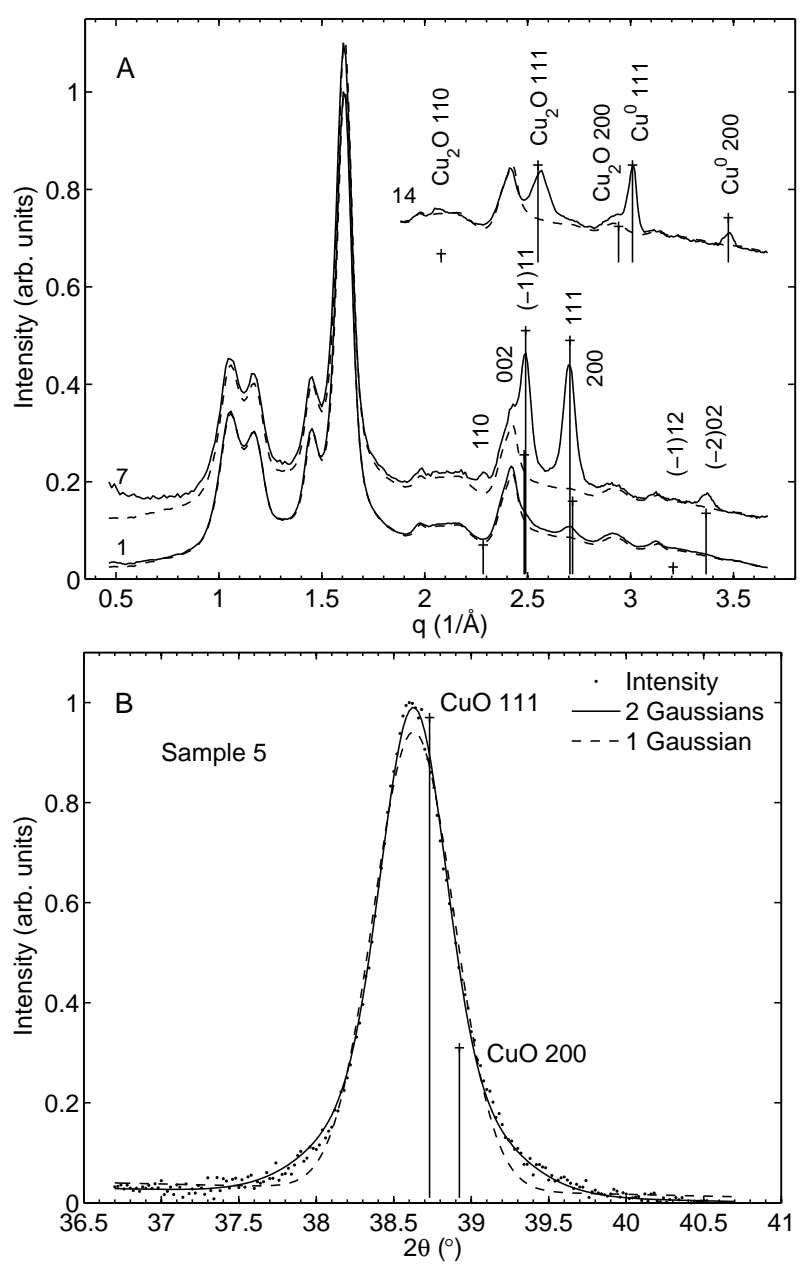

Fig. 2. A) WAXS intensities of the samples 1 and 7 (solid lines) containing $\mathrm{CuO}$ compared with that of MCC (dashed lines). Theoretical $q$-values for reflections and the reflections relative intensities are indicated by vertical lines. The sample 14 contained $\mathrm{Cu}_{2} \mathrm{O}$ and metallic $\mathrm{Cu}$. B) Fits with one or two Gaussians to $\mathrm{CuO}$ reflection 111 measured using a diffractometer for the sample 5. Reflection 200 is ignored in the fit.

$0.01^{\circ}$ and the line shape was Gaussian although slightly asymmetric. The intensities were corrected for absorption and polarization.

\section{Results}

On the basis of the diffraction patterns (Fig. 2) MCC was partially crystalline cellulose I, with a large thickness of crystallites, $\mathrm{B}_{200}=7.4 \pm 0.1 \mathrm{~nm}$. For comparison, for commercial microcrystalline cellulose, Avicel, the thickness of crystallites $\mathrm{B}_{200}$ is $4.7 \mathrm{~nm}$ [31]. By comparing XRD results for the pure MCC and the MCC-Cu nanocomposites it was concluded that the nanoparticle formation did not affect the semi-crystalline structure of MCC.

The shift in the position of the absorption edge as well as the fine details of the XANES data of the samples (Fig. 3, Table 3) indicated, based on the study of
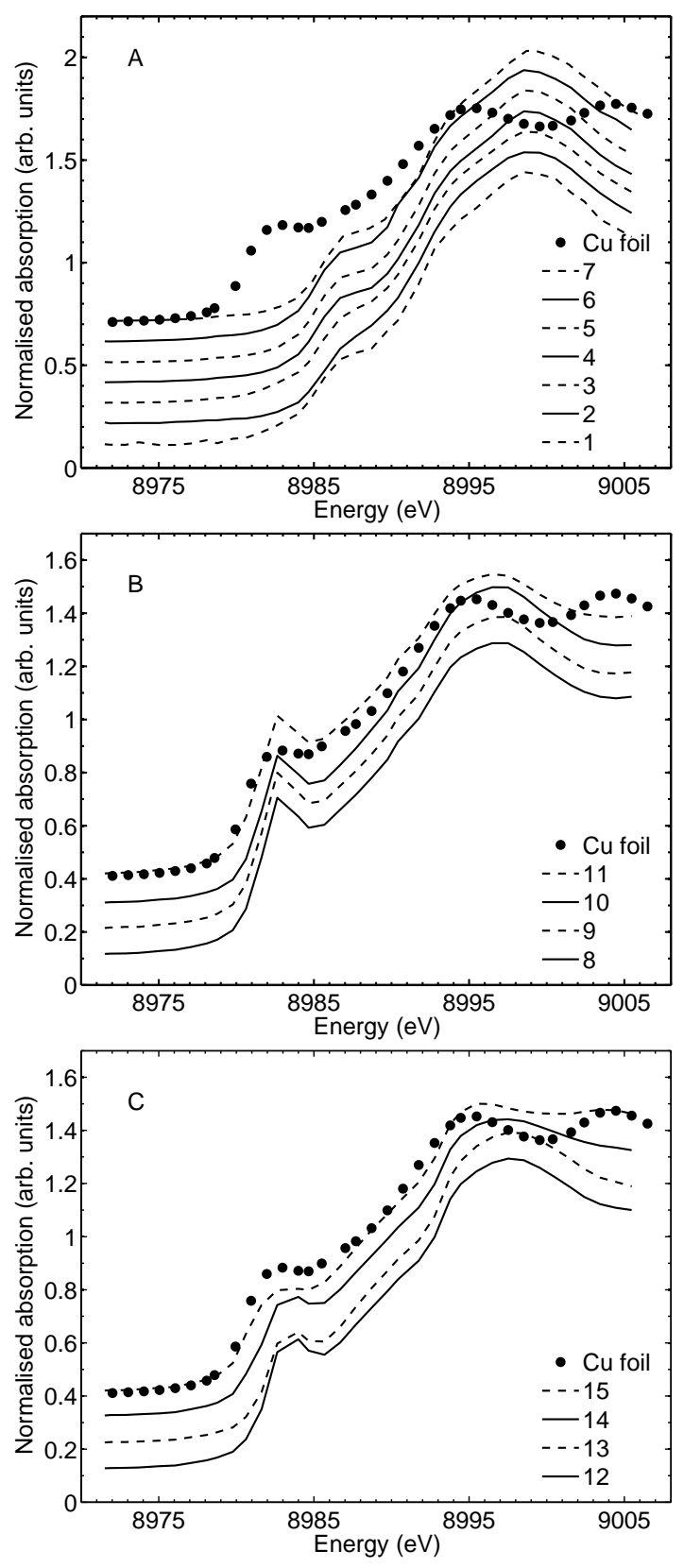

Fig. 3. The absorption edges of the samples $1-7,8-11$, and $12-15$ in normalised units. The curves have been moved in steps of 0.1 vertically for better visualisation.

D'Acapito et al. [32], that $\mathrm{CuO}$ was formed when the reduction was done with cellulose in $\mathrm{NH}_{3} \cdot \mathrm{H}_{2} \mathrm{O}$ medium (Fig. 3, A). Reduction using $\mathrm{NaBH}_{4}$ yielded $\mathrm{Cu}_{2} \mathrm{O}$ (Fig. 3, B) and the samples reduced using $\mathrm{N}_{2} \mathrm{H}_{4} \cdot \mathrm{H}_{2} \mathrm{SO}_{4}$ contained either $\mathrm{Cu}_{2} \mathrm{O}$ or both $\mathrm{Cu}^{0}$ and $\mathrm{Cu}_{2} \mathrm{O}$ (Fig. 3, C).

The XANES results were further clarified by XRD according to which each sample showed reflections of crystalline $\mathrm{Cu}, \mathrm{CuO}$, or $\mathrm{Cu}_{2} \mathrm{O}$ [33]. The average size of the crystallites was determined from the reflection 111 of $\mathrm{Cu}$, $\mathrm{CuO}$, or $\mathrm{Cu}_{2} \mathrm{O}$ (Table 3, Fig. 2). The reflection 111 of $\mathrm{CuO}$ is partly overlapped by the reflection 200 (Fig. 2, B). How- 
Table 3. The crystallite size $\mathrm{B}_{111}$ is determined for $\mathrm{Cu}, \mathrm{CuO}$, and $\mathrm{Cu}_{2} \mathrm{O}$ either with an area detector $\left({ }^{\alpha}\right)$ or with a diffractometer $\left({ }^{\beta}\right) .{ }^{a} \mathrm{Cu}_{2} \mathrm{O}(90 \%) \& \mathrm{Cu}^{0}(10 \%),{ }^{b} \mathrm{Cu}_{2} \mathrm{O}(52 \%) \&$ $\mathrm{Cu}^{0}(48 \%)$, and ${ }^{c} \mathrm{Cu}^{0}(95 \%) \& \mathrm{Cu}_{2} \mathrm{O}(5 \%) . \Delta E=E-E_{0}$ $( \pm 0.2 \mathrm{eV})$ is the shift of the first inflection point of the absorption edge compared to metallic copper $\mathrm{E}_{0}=8980.48 \mathrm{eV}$.

\begin{tabular}{lllllc}
\hline$\#$ & $\mathrm{XRD}$ & $\mathrm{B}_{111}^{\alpha}(\mathrm{nm})$ & $\mathrm{B}_{111}^{\beta}(\mathrm{nm})$ & $\mathrm{XAS}$ & $\Delta E(\mathrm{eV})$ \\
\hline 1 & $\mathrm{CuO}$ & $8.7 \pm 0.1$ & 9.3 & $\mathrm{CuO}$ & 4.8 \\
2 & $\mathrm{CuO}$ & $5.6 \pm 1.1$ & & $\mathrm{CuO}$ & 5.4 \\
3 & $\mathrm{CuO}$ & $5.6 \pm 0.4$ & 5.2 & $\mathrm{CuO}$ & 4.9 \\
4 & $\mathrm{CuO}$ & $8.6 \pm 0.1$ & $13.0 \& 6.3$ & $\mathrm{CuO}$ & 4.8 \\
5 & $\mathrm{CuO}$ & $10.5 \pm 0.1$ & $19.8 \& 7.9$ & $\mathrm{CuO}$ & 4.7 \\
6 & $\mathrm{CuO}$ & $7.9 \pm 0.1$ & $6.2 \& 11.6$ & $\mathrm{CuO}$ & 4.7 \\
7 & $\mathrm{CuO}$ & $9.7 \pm 0.1$ & & $\mathrm{CuO}$ & 5.0 \\
\hline 8 & $\mathrm{Cu}_{2} \mathrm{O}$ & $7.4 \pm 0.2$ & $>29 \& 10.7$ & $\mathrm{Cu}_{2} \mathrm{O}$ & 1.4 \\
9 & $\mathrm{Cu}_{2} \mathrm{O}$ & $13.6 \pm 0.2$ & $>30 \& 10.7$ & $\mathrm{Cu}_{2} \mathrm{O}$ & 1.4 \\
10 & $\mathrm{Cu}_{2} \mathrm{O}$ & $13.9 \pm 0.3$ & $>55 \& 21.2$ & $\mathrm{Cu}_{2} \mathrm{O}$ & 1.4 \\
11 & $\mathrm{Cu}_{2} \mathrm{O}$ & $>15.2$ & & $\mathrm{Cu}_{2} \mathrm{O}$ & 1.4 \\
& $\mathrm{Cu}^{0}{ }^{a}$ & $>20.5$ & & & \\
\hline 12 & $\mathrm{Cu}_{2} \mathrm{O}$ & $8.3 \pm 0.2$ & $4.7 \& 11.9$ & $\mathrm{Cu}_{2} \mathrm{O}$ & 1.6 \\
13 & $\mathrm{Cu}_{2} \mathrm{O}$ & $13.5 \pm 0.2$ & 7.4 & $\mathrm{Cu}_{2} \mathrm{O}$ & 1.6 \\
14 & $\mathrm{Cu}_{2} \mathrm{O}$ & $7.7 \pm 1.5$ & & $\mathrm{Cu}_{2} \mathrm{O}$ & 0.0 \\
& $\mathrm{Cu}^{0} b^{2}$ & $>16.4$ & & & \\
15 & $\mathrm{Cu}^{0}$ & $>17.0$ & $12.3 \&>53$ & $\mathrm{Cu}^{0}$ & -0.1 \\
& $\mathrm{Cu}_{2} \mathrm{O}{ }^{c}$ & $>16.0$ & $5.2 \& 27.5$ & & \\
\hline
\end{tabular}

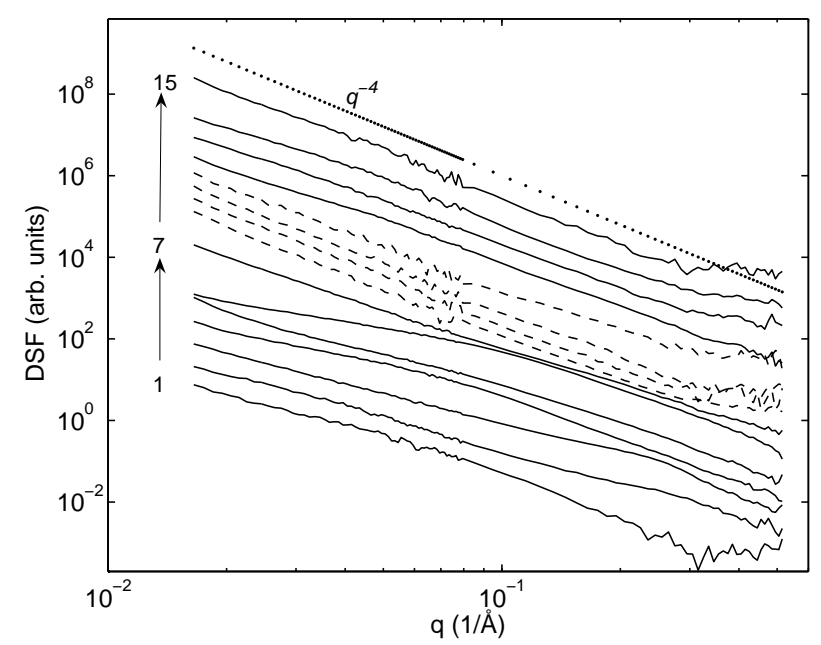

Fig. 4. The differential structure factor, $I_{1}-I_{3}$, for the samples are marked with solid lines (the samples $1-7$ and $12-15$ ) and with dashed lines (the samples $8-11$ ). The dots are a $q^{-4}$ power law for reference.

ever, the 200 reflection is weak compared to the 111 in the case of an ideal powder sample and was not taken into account in the crystallite size determination. See Appendix A for details of the fitting.

The DSFs in Fig. 4 show clearly particle-like scattering for the samples $1-6$, while for other the samples the differential structure factor was mainly a power law indicating either large particle size or aggregation.

The $\mathrm{Cu}-\mathrm{Cu}$ PSF, $S_{\mathrm{bb}}(q)$, could be extracted for 4 samples out of 15 (Fig. 5). For these samples we were able to determine the volume distribution (Fig. 6) assuming the

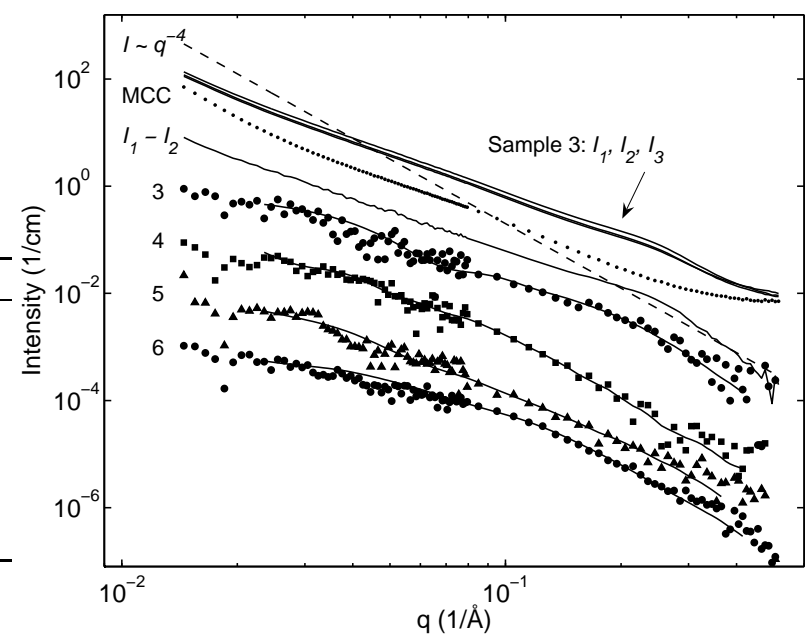

Fig. 5. The ASAXS intensities $I_{1}, I_{2}$, and $I_{3}$ for the sample 3 (solid lines) and the intensity of MCC (dots) are in absolute units. PSFs, $S_{\mathrm{bb}}$, for the samples $3-6$ are shown in symbols with the Monte Carlo fits (solid lines). The PSFs are shifted for clarity and are thus not in absolute units. Dashed line $q^{-4}$ power law.

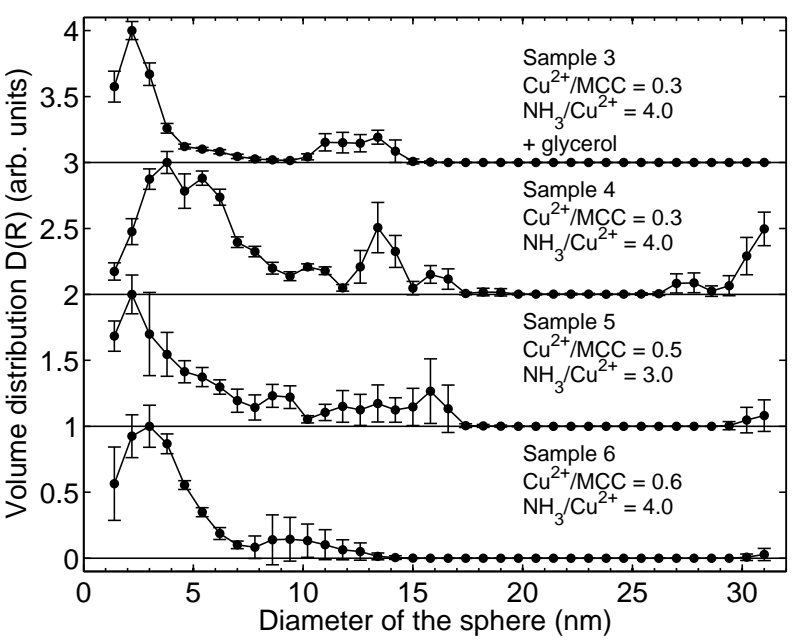

Fig. 6. Volume distributions obtained from the $\mathrm{Cu}-\mathrm{Cu}$ PSFs, $S_{\mathrm{bb}}(q)$, using a Monte Carlo method. The curves have been shifted by 1, 2 or 3 units for clarity. The errorbars are standard deviations. The connecting lines are meant to guide the eye.

particle shape to be spherical. Problems with the extraction of the PSFs are dealt with in Appendix B.

\section{Discussion}

According to the XRD results the nanoparticles did not decrease the crystallinity of the MCC matrix. This indicates that the nanoparticles are anchored on the surface or in the amorphous parts of the microfibrils. The same phenomenon was observed already in previous studies on cellulose noble metal nanocomposites [2,7-9]. Scattering from the nanoparticles revealed that the diffraction maxima of the $\mathrm{CuO}$ crystallites (Fig. 2, B) were shifted to 


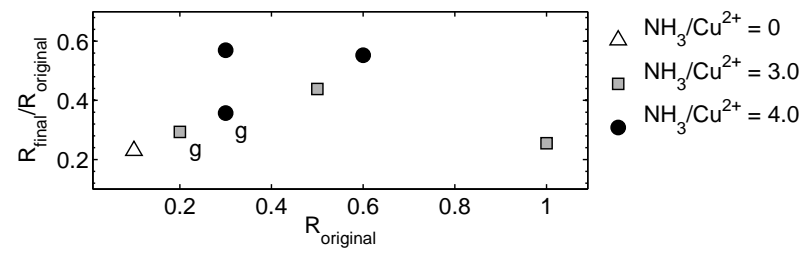

Fig. 7. The ratio of the molar ratio $\mathrm{Cu}^{2+} / \mathrm{MCC}$ in the final product $\left(\mathrm{R}_{\text {final }}\right)$ and the original molar ratio $\mathrm{Cu}^{2+} / \mathrm{MCC}$ in the solution before reduction $\left(\mathrm{R}_{\text {original }}\right)$ as a function of the original ratio for the samples $1-7$ according to x-ray analysis. 'g' in the side of a symbol stands for glycerol that was used in the synthesis.

smaller $2 \theta$ indicated lattice expansion in the small crystallites compared to bulk as observed previously also by Punnoose et al. [34] for $\mathrm{CuO}$ nanocrystallites.

Several previous studies have reported that the formation of $\mathrm{Cu}$ nanoparticles is extremely sensitive to reaction conditions (e.g. [35]). Shim et al. [36] incorporated copper complexes into cellulose acetate and observed formation of copper and $\mathrm{Cu}_{2} \mathrm{O}$ nanoparticles. The size of the particles was $30-120 \mathrm{~nm}$ and depended on the initial concentration of the copper complex and the reaction conditions.

$\mathrm{CuO}$ crystallites were formed in the synthesis when cellulose in $\mathrm{NH}_{3}$ hydrate was used as a reducer without glycerol. The average sizes of the crystallites were $8-10 \mathrm{~nm}$ irrespective of $\mathrm{Cu}^{2+} / \mathrm{MCC}$ molar ratio or the mass percent of copper in the synthesized sample. When glycerol was used in the synthesis the crystallite size was smaller, about $6 \mathrm{~nm}$. However, when glycerol was used only about $30 \%$ of copper remained in the fibre after synthesis, while without glycerol the yield was nearly $60 \%$ (Fig. 7 ). $\mathrm{Cu}^{2+}$ :glycerol complexes form in alkaline conditions at $1: 1$ and and 1:2 molar ratios [37] and glycerol is also known to act as a reducer itself. A competition over the complex formation with $\mathrm{Cu}^{2+}$ exists between cellulose and glycerol.

The composition of the copper-ammine complex has a clear effect on the yield of copper in the samples. When glycerol was not used in the synthesis the highest copper content in the final nanocomposite was achieved when the molar ratio $\mathrm{NH}_{3} / \mathrm{Cu}^{2+}$ was 4.0. Nevertheless, the particle size distribution did not depend on the molar ratio $\mathrm{NH}_{3} / \mathrm{Cu}^{2+}$.

The nanoparticles produced using the stronger reducers, $\mathrm{NaBH}_{4}$ and $\mathrm{N}_{2} \mathrm{H}_{4} \cdot \mathrm{H}_{2} \mathrm{SO}_{4}$, contained both crystalline $\mathrm{Cu}^{0}$ and $\mathrm{Cu}_{2} \mathrm{O}$. With $\mathrm{NaBH}_{4}$, the strongest reducer, the average size of the crystallites was smaller in the samples where glycerol was used accompanied with a slightly smaller yield of copper in the sample. The sample where glycerol was not used contained a small amount of crystalline $\mathrm{Cu}^{0}$ in addition to $\mathrm{Cu}_{2} \mathrm{O}$. A direct correlation was found between the amount of reducer and the crystallite size. With the third reducer, an increase in the concentration of $\mathrm{N}_{2} \mathrm{H}_{4} \cdot \mathrm{H}_{2} \mathrm{SO}_{4}$ resulted in an increase in the amount of $\mathrm{Cu}^{0}$ compared to that of $\mathrm{Cu}_{2} \mathrm{O}$ and also in an increase in the crystallite size. On the other hand, the yield of copper in the samples was close to $100 \%$ independently of the amount of reducer although a slight decrease in the copper yield was observed when large amounts of reducer was used.

According to the SEM data $\mu \mathrm{m}$-sized copper or copper oxide agglomerates were on the surface of the MCC fibre. Similar results have been obtained when nickel and silver nanoparticles were intercalated into MCC using various reducing systems $[8,38]$.

The DSF curve (Fig. 4) of the sample 7 with the highest $\mathrm{Cu}^{2+} / \mathrm{MCC}$ molar ratio shows a power law. Particlelike scattering was observed for the samples $1-6$ indicating that the surfaces of the cellulose fibres were not fully covered with $\mathrm{CuO}$ particles, but instead there were well dispersed $\mathrm{CuO}$ nanoparticles on the surface in addition to the aggregated structures seen using SEM. With the largest $\mathrm{Cu}^{2+}$ /MCC ratio 1.0 in the sample 7 individual $\mathrm{CuO}$ particles of about the crystallite size were no longer present in the samples implying a nearly complete coverage of the fibres or completely agglomerated $\mathrm{CuO}$ particles. A power law in the DSFs can be explained either with polydispersity or by a particle size of length scale larger than about $2 \pi / q_{\min } \approx 40 \mathrm{~nm}$. In all the samples reduced with $\mathrm{NaBH}_{4}$ the $\mathrm{Cu}^{0}$ and $\mathrm{Cu}_{2} \mathrm{O}$ nanoparticles were thus either polydisperse or larger than about $40 \mathrm{~nm}$ or both. XRD results showed that the crystallite size is indeed large (Table 3). The DSFs were nearly identical for $\mathrm{N}_{2} \mathrm{H}_{4} \cdot \mathrm{H}_{2} \mathrm{SO}_{4} / \mathrm{Cu}^{2+}$ molar ratios $0.2-3.4$ and a small hump can be seen in the curves indicating particle scattering. Only for molar ratio 3.9 the power law extends over the whole scattering vector range.

The volume distributions in Fig. 6 are bimodal or nearly bimodal. This is in agreement with the shapes of the diffraction peaks that were fitted better with two Gaussians than with one Gaussian. Since the crystallite sizes and the maxima of the bimodal volume distributions are in close agreement it is likely that the nanoparticles were single crystals rather than polycrystalline. The results may indicate that the smaller particles with sizes less than about $10 \mathrm{~nm}$ are trapped in the MCC fibre, while the larger particles are grown on its surface.

\section{Conclusions}

The structure of the nanoparticles depended on the reducer. The XANES results revealed the oxidation state of copper in the samples that contained very small amounts of copper. This made it easier to spot the right crystalline phase in the XRD patterns. The XANES results gave an precise estimate for the mass percent of copper in the samples. The ASAXS results gave valuable quantitative information on the size distribution of the $\mathrm{CuO}$ nanoparticles and qualitative information on the other sample types.

The reduction of $\mathrm{Cu}^{2+}$ with cellulose in $\mathrm{NH}_{3}$ hydrate medium gave a bimodal $\mathrm{CuO}$ nanoparticle size distribution irrespective of the copper concentration. Based on the crystallite size and the size distribution the $\mathrm{CuO}$ nanoparticles were found to be single crystals rather than polycrystalline. The average crystallite size was smaller when 
glycerol was used in the reaction mixture. The reduction with cellulose in $\mathrm{NH}_{3}$ hydrate medium gave the smallest and most dispersed nanoparticles of the three reduction methods and the coordination of copper with ammonia in the synthesis affected the amount of copper in the synthesized samples.

With $\mathrm{N}_{2} \mathrm{H}_{4} \cdot \mathrm{H}_{2} \mathrm{SO}_{4}$ as a reducing agent $\mathrm{Cu}^{0}$ and $\mathrm{Cu}_{2} \mathrm{O}$ particles were obtained depending on the amount of reducer and nearly $100 \%$ of the copper atoms was adsorbed to the cellulose fibres.

Using $\mathrm{NaBH}_{4}$, the strongest reducer, nanoparticles of $\mathrm{Cu}_{2} \mathrm{O}$ with crystallite sizes larger than $10 \mathrm{~nm}$ were observed when glycerol was used in the synthesis. Without glycerol also a small amount of metallic $\mathrm{Cu}$ nanoparticles was obtained.

The HASYLAB organization is gratefully acknowledged. The graduate school of the University of Helsinki and the Academy of Finland (project 1104837) are thanked for financial support as well as Vilho, Yrjö and Kalle Väisälä foundation.

\section{Appendix A: Crystallite size determination}

The diffractometer had a better resolution than the WAXS setup that was based on the perpendicular transmission geometry. The different values of $B_{111}^{\alpha}$ and $B_{111}^{\beta}$ in Table 3 are explained by the poorer resolution of the perpendicular transmission geometry setup $\left(B_{111}^{\alpha}\right)$. With the diffractometer a good fit of a 111 reflection was usually obtained by fitting two Gaussians at the same position with different FWHM (Fig. 2, B). When two values are given in Table 3 the particle size that is given first is the one that had more weight in the fitted result. One Gaussian was fitted to the diffraction peak in the case of the perpendicular transmission geometry. If the FWHM of the reflection was less than $2 \mathrm{FWHM}_{\text {inst }}$ the crystallite size was considered to be a nominal minimum value. The relative errors of the diffractometer results were about $1 \%$.

\section{Appendix B: Solving of the PSFs}

For the sample 3 the $\mathrm{Cu}-\mathrm{Cu}$ PSFs, $S_{\mathrm{bb}}(q)$, could be solved without any modification of the experimental intensity levels. For intensities from other the samples some modification had to be done to be able to solve the PSFs reliably. Since in some samples the particles were as monodisperse as in the simulation, it was possible to compare the solved $S_{\mathrm{ab}}(q)$ to the one obtained from the simulation. The correct level of the absolute intensity at one of the energies was then adjusted by multiplying with a constant close to 1 until the oscillations of the cross-term resembled those from the simulation. The $S_{\mathrm{bb}}(q)$ obtained using these intensity levels was considered acceptable. The solving of the PSFs with three energies using the derivative method gave practically the same result as the direct method for $S_{\mathrm{bb}}(q)$, but $S_{\mathrm{ab}}(q)$ differed due to the small number of points in the derivation. Otherwise the method was useful, since the quality of the data was easily visualized.

\section{References}

1. A. Shulman, D.O. White, Chem.-Biol. Interactions 6, 407 (1973)

2. N.E. Kotelnikova, E.F. Panarin, A.V. Shchukarev, R. Serimaa, T. Paakkari, K. Jokela, S.V. Shilov, N.P. Kudina, G. Wegener, E. Windeisen et al., Carbohyd. Polym. 38(3), 239 (1999)

3. R.E. O'Connor, J.B. Schwartz, Pharm. Res. 10(3), 356 (1993)

4. V.E. Rijenkov, I.V. Okunevich, G.A. Petropavlovsky, N.E. Kotelnikova, Phisiol. Experim. Terapia 5, 6 (1986)

5. N. Kabay, M. Demircioglu, S. Yayli, M. Yuksel, M. Saglam, P.R. Levinson, Sep. Sci. Technol. 34, 41 (1999)

6. E. Norkus, J. Vaičiūnienè, T. Vuorinen, D.L. Macalady, Carbohydr. Polymer 55(1), 47 (2004)

7. J. He, T. Kunitake, A. Nakao, Chem. Mater. 15(23), 4401 (2003)

8. N. Kotelnikova, E.L. Lisenko, R. Serimaa, K. Vainio, V. Lavrent'ev, D. Medvedeva, A.L. Shachmin, N.N. Saprikina, N.P. Novoselov, Book of papers of postgraduate students of the UTaD 10, 175 (2005)

9. N. Kotelnikova, T. Paakkari, R. Serimaa, G. Wegener, V. Kotelnikov, V. Demidov, A. Schukarev, E. Windeisen, H. Knozinger, V. Kudryashov et al., Macromol. Symp. 114, 165 (1997)

10. B.R. Evans, H.M. O'Neil, V.P. Malyvanh, I. Lee, J. Woodward, Biosens. Bioelectron. 18(7), 917 (2003)

11. K. Pirkkalainen, U. Vainio, K. Kisko, T. Elbra, T. Kohout, N.E. Kotelnikova, R. Serimaa, J. Appl. Crystallogr. (2006), submitted.

12. F. Quignard, A. Choplin, Chem. Comm. (1), 21 (2001)

13. K.R. Reddy, N.S. Kumar, B. Sreedhar, M.L. Kantam, J. Mol. Catal. A: Chem. 252, 136 (2006)

14. V.S. Gurin, V.P. Petranovskii, A.N. Pestryakov, A. Kryazhov, O. Ozhereliev, M.A. Hernandes, A.A. Alexeenko, Eur. Phys. J. D 24, 381 (2003)

15. P. Carniti, A. Gervasini, V.H. Modica, N. Ravasio, Appl. Catal., B 28, 175 (2000)

16. S.H. Wu, D.H. Chen, J. Colloid Interface Sci. 273, 165 (2004)

17. N.A. Dhas, C.P. Raj, A. Gedanken, Chem. Mater. 10, 1446 (1998)

18. I. Lisiecki, F. Billoudet, M.P. Pileni, J. Mol. Liq. 72, 251 (1997)

19. J.P. Simon, O. Lyon, in Resonant anomalous $x$-ray scattering (Elsevier Science V.B., North-Holland, 1994)

20. O. Lyon, J.P. Simon, Phys. Rev. B 35(10), 5164 (1987)

21. H.G. Haubold, K. Gruenhagen, M. Wagener, H. Jungbluth, H. Heer, A. Pfeil, H. Rongen, G. Brandenberg, R. Moeller, J. Matzerath et al., Rev. Sci. Instrum. 60(7), 1943 (1989)

22. C.T. Chantler, K. Olsen, R.A. Dragoset, A.R. Kishore, S.A. Kotochigova, D.S. Zucker, X-ray form factor, attenuation and scattering tables (version 2.1), National Institute of Standards and Technology, Gaithersburg, MD. (2005)

23. T. Vad, F. Hajbolouri, H.G. Haubold, G.G. Scherer, A. Wokaun, J. Phys. Chem. B 108, 12442 (2004)

24. G. Evans, R.F. Pettifer, J. Appl. Crystallogr. 34(1), 82 (2001)

25. S. Brennan, P.L. Cowan, Rev. Sci. Instrum. 63(1), 850 (1992) 
26. P.H. Fuoss, P. Eisenberg, W.K. Warburton, A. Bienenstock, Phys. Rev. Lett. 46(23), 1537 (1981)

27. R. Serimaa, V. Eteläniemi, T. Laitalainen, A. Bienenstock, S. Vahvaselkä, T. Paakkari, Inorg. Chem. 36, 5574 (1997)

28. R.G. Munro, Phys. Rev. B 25(8), 5037 (1982)

29. A. Guinier, X-ray Diffraction. In Crystals, Imperfect Crystals, and Amorphous Bodies (Dover publications, Inc., New York, 1994), chapters 4.7, 5, 10.

30. S. Martelli, P.E. di Nunzio, Part. Part. Syst. Charact. 19, 247 (2002)

31. S. Andersson, H. Wikberg, E. Pesonen, S.L. Maunu, R. Serimaa, Trees 18, 346 (2004)

32. F.D. D'Acapito, S. Colonna, S. Mobilio, F. Gonella, E. Cattaruzza, P. Mazzoldi, Appl. Phys. Lett. 71(18), 2611 (1997)

33. H.E. Swanson, E. Tatge, eds., Standard X-ray Powder Diffraction Patterns, Vol. I, II of NBS Circular 539 (U.S. GPO, Washington, D.C., 1953)

34. A. Punnoose, H. Magnone, M.S. Seehra, J. Bonevich, Phys. Rev. B 64(17), 174420 (2001)

35. Y. Song, E. Doomes, J. Prindle, R. Tiisworth, J. Hormes, C.S. Kumar, J. Phys. Chem. B 109, 9330 (2005)

36. I.W. Shim, W.T. Noh, J. Kwon, J.Y. Cho, K.S. Kim, D.H. Kang, Bull. Korean Chem. Soc. 23(4), 563 (2002)

37. E. Norkus, J. Appl. Electrochem. 30, 1163 (2000)

38. N. Kotelnikova, M. Stoll, G. Wegener, E. Windeisen, M. Wenzkowski, V. Demidov, E. Aleksandrova, Cellul. Chem. Technol. 37(1-2), 51 (2003) 